\title{
Conservation and Management of the Culture of Bears
}

\author{
Christopher Servheen ${ }^{1}$ and Kerry Gunther ${ }^{2}$ \\ ${ }^{1}$ University of Montana \\ ${ }^{2}$ Yellowstone National Park
}

December 6, 2021

\begin{abstract}
ABSTRACT: Culture is widely accepted as an important social factor present across a wide range of species. Bears have a culture as defined as behavioral traditions inherited though social learning usually from mothers to offspring. Successful bear cultures can enhance fitness and resource exploitation benefits. In contrast, some bear cultures related to response to humans and human-related foods can be maladaptive and result in reduced fitness and direct mortality. In environments with minimal human influence most bear culture has evolved over generations to be beneficial and well adapted to enhance fitness. However, most bears across the world do not live in areas with minimal human influence and in these areas, bear culture is often changed by bear interactions with humans, usually to the detriment of bear survival. We highlight the importance of identifying unique bear cultural traits that allow efficient use of local resources and the value of careful management to preserve these adaptive cultural behaviors. It is also important to select against maladaptive cultural behaviors that are usually related to humans inorder to reduce human-bear conflicts and high bear mortality. We use examples from Yellowstone National Park to demonstrate how long-term management to reduce maladaptive bear cultures related to humans has resulted in healthy bear populations and a low level of human-bear conflict in spite of a high number of Park visitors in close association with bears.
\end{abstract}

\section{Hosted file}

Conserv and manage of culture in bears.docx available at https://authorea.com/users/449811/ articles/548283-conservation-and-management-of-the-culture-of-bears 